\title{
Development of blood pressure and cardiac reflexes in the frog Pseudis paradoxsus
}

\author{
WARREN W. BURGGREN, J. EDUARDO BICUDO, \\ MOGENS L. GLASS, AND AUGUSTO S. ABE \\ Department of Biological Sciences, University of Nevada, Las Vegas, Nevada 89154; Biosciences \\ Institute, Department of Physiology, University of São Paulo, 05421 São Paulo; Department of \\ Physiology, Faculty of Medicine of Ribeirão Preto, University of São Paulo, 14.049 Ribeirão Preto; \\ and Biosciences Institute, Campus de Rio Claro, Universidade Estadual Paulista, Rio Claro, Brazil
}

Burggren, Warren W., J. Eduardo Bicudo, Mogens L. Glass, and Augusto S. Abe. Development of blood pressure and cardiac reflexes in the frog Pseudis paradoxsus. Am. J. Physiol. 263 (Regulatory Integrative Comp. Physiol. 32: R602R608, 1992.-Systemic arterial blood pressure and heart rate $\left(\mathrm{f}_{\mathrm{H}}\right)$ were measured in unanesthetized, unrestrained larvae and adults of the paradoxical frog, Pseudis paradoxus from São Paulo State in Brazil. Four developmental groups were used, representing the complete transition from aquatic larvae to primarily air-breathing adults. $\mathrm{f}_{\mathrm{H}}(49-66$ beats/min) was not significantly affected by development, whereas mean arterial blood pressure was strongly affected, being lowest in the stage 37-39 larvae $(10 \mathrm{mmHg})$, intermediate in the stage $44-45$ larvae (18 $\mathrm{mmHg}$ ), and highest in the juveniles and adults (31 and 30 $\mathrm{mmHg}$, respectively). Blood pressure was not significantly correlated with body mass, which was greatest in the youngest larvae and smallest in the juveniles. In the youngest larvae studied (stages 37-39), lung ventilation was infrequent, causing a slight decrease in arterial blood pressure but no change in heart rate. Lung ventilation was more frequent in stages 44-45 larvae and nearly continuous in juveniles and adults floating at the surface. Bradycardia during both forced and voluntary diving was observed in almost every advanced larva, juvenile, and adult but in only one of four young larvae. Developmentally related changes in blood pressure were not complete until metamorphosis, whereas diving bradycardia was present at an earlier stage.

circulation; heart rate; diving reflexes

FEW VERTEBRATES undergo as rapid and as large a developmental transformation as anuran amphibians during metamorphosis. During ontogeny, anurans change from completely aquatic animals to adults that at least breathe air if not adopt a terrestrial way of life. Considerable effort has been focused on determining changes in respiration during amphibian development, including partitioning of gas exchange between air and water (and between gills, lungs, and skin), on the special role of the skin in larval and amphibian respiration, and on the control of both branchial and pulmonary ventilation (for reviews see Refs. $3,4,7,13,14)$.

Changes in the cardiovascular anatomy of anurans occur concurrent with developmental changes in respiratory structures and processes. Because cardiovascular measurements in small animals such as these are technically difficult, knowledge of the ontogeny of cardiovascular function in anuran amphibians lags far behind understanding of developmental changes in respiratory processes or of cardiovascular anatomical changes. To date, most physiological studies have concentrated either on the pharmacological changes of the developing anuran heart, using a combination of in vivo and in vitro techniques (e.g., Refs. 5, 19), or have studied the in vivo regulation of heart rate (6). Moreover, only one study (22) has examined how the hemodynamics of the larval anuran heart change with metamorphosis to the adult. Blood pressure was measured in the ventricle, conus arteriosus, and truncus arteriosus of a wide range of developmental stages of the bullfrog Rana catesbeiana, and arterial blood pressure was reported to increase throughout larval development. Unfortunately, the relatively small size of even bullfrog larvae necessitates the use of a microelectrode pressure recording system on pithed or anesthetized animals. Therefore the effects of development and metamorphosis on blood pressure in unrestrained intact anurans remain unexplored, as does the point in development where complex cardiovascular responses (e.g., diving bradycardia) first occur.

The present study on the paradoxical frog (Pseudis paradoxsus) capitalizes on the unusually large size of the larval stages to permit measurements of blood pressure in conscious, freely swimming specimens. $P$. paradoxsus, common in Southern Brazil, is so named because the larvae, not the adults, attain the largest size during the life cycle. The larvae of Pseudis can achieve a mass of over $150 \mathrm{~g}$ and a length of $25 \mathrm{~cm}$ (11), making them among the largest of all anuran larvae. Upon metamorphosis, there is a radical reduction in size and mass, with some recovery in size as growth to sexual maturity occurs. Nevertheless, the adults attain a maximum body mass of only $\sim 35 \mathrm{~g}$, far less than that of the early larval stages.

In the present study, we chronically cannulated the sciatic artery in a hindlimb of aquatic larvae, of metamorphosing larvae, and of postmetamorphic juveniles and mature adults. Changes in arterial blood pressure associated with development in freely swimming animals were recorded, as were the onset and development of the cardiovascular responses to intermittent breathing and diving.

\section{METHODS}

Animals

Experiments were performed on 33 specimens of the paradoxical frog, $P$. paradoxsus. Larvae, metamorphosing animals, and juvenile and adult frogs were collected from artificial ponds used for fish aquaculture in the vicinity of Ribeirão Preto, São Paulo State, Brazil, during the months of February and March 1990. All animals were maintained in water at $23-27^{\circ} \mathrm{C}$ and at an 12:12-h light-dark cycle.

The natural history and developmental biology of $P$. paradoxsus have been described by Cais (11). Briefly, the present study used four distinctly different developmental groups, the earliest consisting of stage 37-39 larvae [staging system from 
Cais (11), modified from Gosner (17)]. These larvae had small hindlimbs but no forelimbs, and the tail showed no signs of degeneration. Larvae at this stage were completely aquatic but had begun to surface to take occasional air breaths. These larvae also had the largest mean body mass $(42 \mathrm{~g}$, Table 1$)$. The second group, stages 42-45 (mean body mass $13 \mathrm{~g}$ ), consisted of individuals approaching metamorphic climax. Forelimbs had emerged fully, and the gills had almost, if not completely, degenerated. The tail had obviously degenerated, and the animals could hop effectively on land. The third group, "juvenile frogs," consisted of small, sexually immature individuals that we arbitrarily defined as weighing $\leq 15 \mathrm{~g}$ (mean body mass $11 \mathrm{~g}$ ) and included both individuals that had undergone metamorphosis while in captivity as well as animals collected as juveniles. The fourth group, designated as "adults," weighed $\geq 23 \mathrm{~g}$ (mean body mass $30 \mathrm{~g}$ ), and were all collected from their natural habitat as adults.

\section{Surgical Procedures}

Pseudis were anesthetized by submersion for several minutes in a $5 \%$ solution of ether in water. After cessation of locomotor and ventilatory movements, the animal was removed from the anesthetic, placed on the stage of binocular dissecting microscope, and covered with paper towel soaked in $5 \%$ ether. A small longitudinal incision in the skin on the dorsal surface of the left hindlimb exposed the left sciatic artery, which was then occlusively cannulated with a $50-\mathrm{cm}$ length of PE-50 cannula $(0.97$ $\mathrm{mm}$ OD). The cannula tip had been previously drawn down to an outside diameter of $\sim 0.5 \mathrm{~mm}$ using a small flame. The cannula was filled with heparinized saline and exteriorized through the dorsal surface of the leg and the incision closed with interrupted sutures (for details, see Ref. 9 as an example). The present study has extended this sciatic arterial cannulation technique to frogs as small as $6 \mathrm{~g}$. In two very large larvae with hindlimbs of inadequate size for sciatic artery cannulation, the cervical artery was cannulated with PE-50 cannulas (tip diam reduced as described above) using a technique developed for arterial cannulation of large goldfish (1).

After cannulation, $\sim 0.2$ IU heparin/g body mass was injected via the cannula. The animal was placed in a 2-liter translucent holding tank containing $\sim 10 \mathrm{~cm}$ of water, where all subsequent blood pressure measurements were made.

\section{Pressure Measurement}

The sciatic artery cannula was attached via a three-way tap to a COBE pressure transducer connected to a Narco Four A Physiograph with rectilinear pens. The transducer was also connected via a second three-way tap to two saline-filled cannulas, one placed in the container with the animal (to obtain 0 pressure) and a second cannula elevated a measured distance above the surface of the container. In this way, the transducer could be calibrated frequently by switching from the sciatic arterial cannula in sequence to the two calibration cannulae.

Systolic pressure $\left(\mathrm{P}_{\mathrm{sys}}\right)$, diastolic pressure $\left(\mathrm{P}_{\text {dia }}\right)$, and pulse pressure $\left(\mathrm{P}_{\text {pulse }}\right)$ were determined from the blood pressure signal. The standard formula for mean blood pressure in mammals can only be applied in modified form to lower vertebrates with lower heart rates and highly compliant vessels (2). Accordingly, mean blood pressure $\left(\mathrm{P}_{\text {mean }}\right)$ was calculated from $\mathrm{P}_{\text {dia }}$ and $\mathrm{P}_{\text {pulse }}$ using the formula $\mathrm{P}_{\text {dia }} \pm 0.25 \mathrm{P}_{\text {pulse }}$, which was determined empirically from detailed analysis of sciatic arterial pressure waveforms from five Pseudis. (This formula was also used for determination of $\mathrm{P}_{\text {mean }}$ in the two larvae in which cervical arterial pressure was measured.)

Experimental protocol. Pseudis were placed in the holding tank immediately after surgery. Pseudis of all developmental stages usually began buccal movements within a few minutes and recovered fully within $1 \mathrm{~h}$, judged by normal spontaneous locomotion, gill and/or lung ventilation, and response to visual and tactile stimuli. A few adults required artificial lung ventilation to hasten recovery. This was achieved by tracheal intubation followed by repeated inflation and deflation of the lungs using an air-filled syringe.

Blood pressure measurements were made as described above 2-4 h after surgery only on Pseudis that were completely recovered from anesthesia. At that time, blood pressure was recorded continuously over a randomly selected 5-min period in which animals were floating at the surface with free access to air (i.e., not actively diving far beneath the water surface). The average heart rate $\left(\mathrm{f}_{\mathrm{H}}\right), \mathrm{P}_{\text {sys }}, \mathrm{P}_{\text {dia }}, \mathrm{P}_{\text {pulse }}$, and $\mathrm{P}_{\text {mean }}$ during the 5 -min period was then calculated. In 16 of 33 Pseudis examined, the sciatic arterial cannula was still intact and without internal clotting 12-24 h after surgery (generally on the 2 nd day). Arterial blood pressure was recorded a second time in these individuals, and the results were compared (see below).

Cardiovascular responses associated with alternating periods of lung ventilation and apnea during submergence were also assessed in most of the cannulated animals 2-4 h after surgery. Metamorphosing larvae (stages 42-45) and juvenile and adult frogs tended to float at the surface, taking air breaths at irregular intervals. Lung ventilation could be easily monitored visually and noted on the blood pressure records by manually activating an event marker. In several metamorphosing larvae, juvenile, and adult frogs, cardiovascular variables were recorded continuously before, during, and after completely voluntary dives lasting from $<1$ up to $30 \mathrm{~min}$. In addition, in all Pseudis a forced diving was carried out. Forced diving was initiated in different ways, depending on developmental stage. After blood pressure had been recorded for several minutes, a $5-\mathrm{cm}$ square block of 2-cm-thick Styrofoam was gently placed on the water surface directly above the animal. Even though this initiated a "forced" dive, in fact larvae very rarely struggled, rather remaining motionless while submerged. After 3-10 min, the larvae would typically begin a slight swimming motion, just sufficient to move to the side of the Styrofoam block to surface and take a breath. In this way, the investigators specified the start of the dive, but essentially each larva controlled the duration and termination of the dive.

A different technique was employed for juveniles and adults, because early trials revealed that they would usually swim to the side of the Styrofoam block as soon as it was placed on the water surface above their head. Consequently, a Styrofoam lid covering the entire surface of the container was employed. At the beginning of the experiment, recordings were made on quietly resting frogs with the lid elevated $\sim 1 \mathrm{~cm}$ above the water surface. A forced dive was then initiated by gently lowering the lid onto the surface of the water. Each frog normally remained quietly submerged for several minutes. After a variable period of submergence, the frog would begin to move to the surface, and at this time the dive was terminated by lifting the lid and allowing the frog to breathe air.

Because there was minute-to-minute variation in pre-dive $f_{H}$ and because diving bradycardia was not particularly marked in several animals, a criterion was established to distinguish a "true" diving response from what might be normal variation in $f_{H}$ not associated with diving. A persistent ( $\geq 1 \mathrm{~min}$ ) reduction in $f_{H}$ from predive values of $\geq 10 \%$ within the first 5 min of a dive was required to score an animal as showing a diving bradycardia. The lowest mean value of $f_{H}$ measured over a 1-min period during this initial $5 \mathrm{~min}$ of diving was subsequently plotted as the " $\mathrm{f}_{\mathrm{H}}$ during diving."

\section{Statistical Analysis}

Cardiovascular variables are presented as means \pm SD. Linear regression (least-squares methods) was used to determine 
the relationship between body mass and blood pressure in the four developmental groups studied. One-way analysis of variance (ANOVA) was used to assess the significance of differences between group means followed by Student-Newman-Keuls test to test differences between specific groups, where appropriate. The significance of any changes in measured cardiovascular variables between the 2 - to 4 - and 12 - to 24 -h measurement periods within individuals was assessed with the Student's paired $t$ test. A fiducial level of 0.05 was used in all statistical analyses.

\section{RESULTS}

\section{Basic Cardiovascular Variables}

Mean values for measured and calculated cardiovascular variables in four developmental groups of $P$. paradoxsus are presented in Table 1 . The data were collected while animals exhibited normal undisturbed lung ventilation patterns (i.e., not diving). In stage 42-45 larvae and in adults $\mathrm{f}_{\mathrm{H}}$ measured 2-4 $\mathrm{h}$ after surgery was significantly higher (by $\sim 1 / 3$ ) than that measured $12-24$ h after surgery (Table 1), obviously indicating some degree of postsurgical stress. However, all measured aspects of blood pressure were not significantly different between 2-4 and 12-24 $\mathrm{h}$ after surgery. Because the number of observations is far greater for the period $2-4 \mathrm{~h}$ in each developmental group examined, the data presentation centers on this first group of measurements.

Heart rate $2-4 \mathrm{~h}$ after surgery ranged from an average of 49 to 66 beats/min, with no significant difference occurring between developmental groups. Unlike $\mathrm{f}_{\mathrm{H}}$, however, $\mathrm{P}_{\text {sys }}, \mathrm{P}_{\text {dia }}, \mathrm{P}_{\text {pulse }}$, and $\mathrm{P}_{\text {mean }}$ measured 2-4 $\mathrm{h}$ after surgery all changed significantly with development in Pseudis (Table 1). The mean values of all four measured blood pressure variables in the youngest (largest) aquatic larvae were significantly lower (Student-Newman-Keuls test) than in the older stage 42-45 larvae, which were in turn were significantly lower than in the juveniles or adults. There were no significant differences between these latter two groups.

Figure 1 illustrates the relationship between mean blood pressure and body mass and depicts the distinct rise in pressure during larval development to reach the maximum pressure levels of juveniles and adults. Because of considerable variation in body mass within a developmental class (especially the postmetamorphic Pseudis), the data for each group were analyzed to determine whether any cardiovascular variable was correlated with body mass. Linear regression analysis disclosed that 1) there was no significant correlation between body mass and heart rate or blood pressure within any developmental stage $(P>0.1$ for the correlation coefficient, $r$, for each variable in each group) and 2) there was no significant correlation between body mass and any cardiovascular variable when a single analysis was performed grouping all animals together.

\section{Cardiovascular Responses to Intermittent Lung Ventilation and Diving}

Stage 37-39. Gill ventilation in the four stage 37-39 larvae in air-equilibrated water was usually continuous (60-70 breaths/min). However, lung ventilation at this developmental stage occurred infrequently, even in intact undisturbed animals. Breathing activity varied from a single breath up to a series of 10 breaths spaced by only 1 or $2 \mathrm{~s}$. Periods of apnea also ranged widely from $<1$ to $>30$ $\min$.

Only one of the four stage 37-39 larvae exhibited lung ventilation in the 2 - to 4 -h period after surgery. Thus statistical analysis of cardiovascular data related to intermittent breathing (i.e., development of diving bradycardia) was not possible. However, observations on this single larva are important, for they show at the very least that cardiovascular reflexes can be present at this stage, which was the earliest developmental stage of all Pseudis examined. Lung ventilation in this individual was accompanied by a transient fall in systemic arterial blood pressure (Fig. 2, top). Forced diving in this individual induced a $25 \%$ reduction in $\mathrm{f}_{\mathrm{H}}$ that occurred within one heartbeat of the commencement of diving (Figs. 2, bottom, and 3, top left) and usually remained in force throughout the dive. Interestingly, this individual also showed spontaneous changes in $\mathrm{f}_{\mathrm{H}}$ when body contact was accidentally made with an adult Pseudis swimming in the same container and also when a shadow moved over the animal.

Stages 42-45. By stages 42-45, larvae were breathing air at the surface much more frequently (1-3 breaths/ min) than they did at stages 37-39, although rhythmic buccal movements (presumptive ventilation of the degenerating gills) persisted. Periods of apnea generally did not

Table 1. Basic cardiovascular variables in unanesthetized larval, juvenile, and adult Pseudis paradoxus

\begin{tabular}{|c|c|c|c|c|c|c|c|c|c|c|c|c|c|}
\hline \multirow{3}{*}{$\begin{array}{l}\text { Developmental } \\
\text { Stage }\end{array}$} & \multirow{3}{*}{ Mass } & \multicolumn{6}{|c|}{ 2-4 h Postoperative } & \multicolumn{6}{|c|}{ 12-24 h Postoperative } \\
\hline & & \multirow{2}{*}{$n$} & \multirow{2}{*}{$\begin{array}{c}f_{H} \\
\text { beats } / \text { min }\end{array}$} & \multicolumn{4}{|c|}{ Pressure, $\mathrm{mmHg}$} & \multirow{2}{*}{$n$} & \multirow{2}{*}{$\begin{array}{c}f_{H}, \\
\text { beats/min }\end{array}$} & \multicolumn{4}{|c|}{ Pressure, $\mathrm{mmHg}$} \\
\hline & & & & Systolic & Diastolic & Pulse & Mean & & & Systolic & Diastolic & Pulse & Mean \\
\hline \multirow[t]{2}{*}{ Larvae (G37-39) } & 41.9 & 4 & 60 & 13 & 8 & 4 & $1 C$ & 1 & $(43)$ & (17) & $(10)$ & (7) & (12) \\
\hline & \pm 8.9 & & \pm 12 & \pm 4 & \pm 2 & \pm 2 & \pm 3 & & & & & & \\
\hline \multirow[t]{2}{*}{ Larvae (G42-45) } & 13.3 & 10 & 66 & 25 & 16 & 9 & 18 & 6 & 48 & 26 & 16 & 10 & 19 \\
\hline & \pm 5.0 & & \pm 15 & \pm 5 & \pm 3 & \pm 3 & \pm 3 & & $\pm 11^{*}$ & \pm 8 & \pm 5 & \pm 4 & \pm 5 \\
\hline \multirow{2}{*}{ Juveniles $(<15 \mathrm{~g})$} & 10.9 & 7 & 49 & 41 & 27 & 13 & 31 & 6 & 46 & 43 & 30 & $\overline{13}$ & 34 \\
\hline & \pm 3.2 & & \pm 8 & \pm 6 & \pm 3 & \pm 5 & \pm 4 & & \pm 4 & \pm 4 & \pm 2 & \pm 4 & \pm 5 \\
\hline \multirow[t]{2}{*}{ Adults ( $>15 \mathrm{~g}$ ) } & 29.8 & 12 & 54 & 42 & 26 & 16 & 30 & 3 & 38 & 42 & 29 & 12 & 32 \\
\hline & \pm 5.8 & & \pm 9 & \pm 7 & \pm 6 & \pm 3 & \pm 6 & & $\pm 1^{*}$ & \pm 5 & \pm 4 & \pm 2 & \pm 5 \\
\hline$P$ & $<0.001$ & & NS & $<0.001$ & $<0.001$ & $<0.001$ & $<0.001$ & & NS & $<0.01$ & $<0.001$ & NS & $<0.001$ \\
\hline
\end{tabular}

Values are means \pm SD. Larval developmental stages according to Gosner classification scheme, modified by Cais (11). ${ }^{*}$ Significantly lower than corresponding 2 - to 4 -h value, determined by paired $t$ test of 2 - to 4 -h and 12 - to 24 -h measurements in individuals retaining patent cannula. 


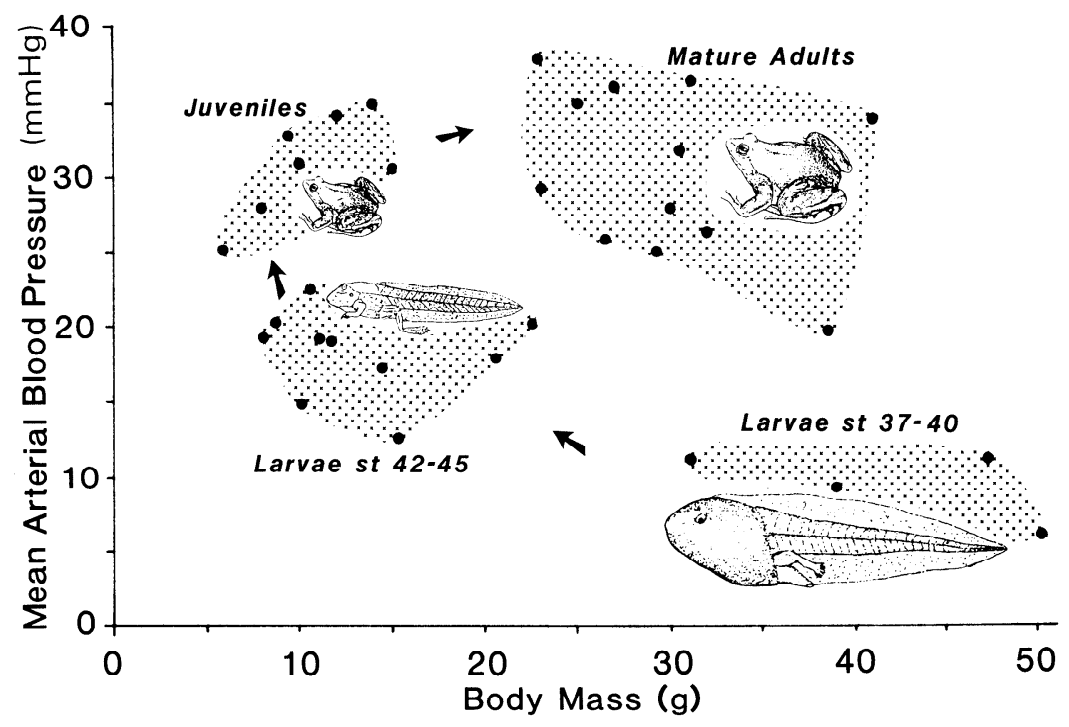

Fig. 1. Mean arterial blood pressure in conscious, undisturbed aquatic larvae (stage 37-39), metamorphosing larvae (stage 42-45), postmetamorphic juveniles, and sexually mature adults. Data are plotted as a function of body mass to show simultaneous changes in body mass and mean blood pressure during development. Linear regression analysis revealed that there was no significant relationship between mean blood pressure and body mass within each of 3 developmental groups (see text for further details).

exceed 2 min. No significant changes in $\mathrm{f}_{\mathrm{H}}$ or $\mathrm{P}_{\mathrm{sys}}, \mathrm{P}_{\mathrm{dia}}$, $\mathrm{P}_{\text {pulse }}$, and $\mathrm{P}_{\text {mean }}$ were associated with intermittent lung ventilation and apnea while floating at the water surface. Voluntary dives of $>2$ min were observed in several stage 42-45 larvae, however. Invariably, a bradycardia occurred during these dives, beginning within $20 \mathrm{~s}$ of the dive and becoming more pronounced as the dive progressed. If the bradycardia was relatively mild (e.g., 10-15\% decrease from predive $f_{H}$ ), then beat-to-beat $f_{H}$ was relatively constant during diving. If diving bradycardia was more severe, then irregularly occurring extra-long interbeat intervals were common (Fig. 4). Regardless of voluntary dive duration and magnitude of the bradycardia, $f_{H}$ returned to predive levels within a few heartbeats of resumption of air breathing in stages 44-45. In one stage 44-45 larva there was an "anticipatory" increase in $\mathrm{f}_{\mathrm{H}}$, developing $\sim 1 \mathrm{~min}$ before the voluntary end of the dive.

Forced dives (with voluntary dive termination) were carried out on eight stage 42-45 larvae. Considerable variation in predive $f_{H}$ was evident (Fig. 3), with the highest predive rate being more than double the lowest. Nonetheless, seven of eight larvae developed a diving bradycardia by our criterion (i.e., $\geq 10 \%$ reduction in $\mathrm{f}_{\mathrm{H}}$ within 5 min of the beginning of the dive; Fig. 3). Indeed, all

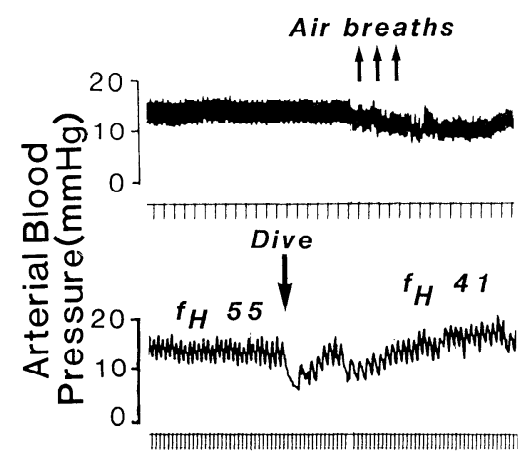

Fig. 2. Arterial blood pressure (cervical artery) and heart rate measured in a 30.8-g stage 37 larval $P$. paradoxsus. Top: changes in arterial blood pressure associated with voluntary intermittent air breathing. Gill ventilation was continuous during course of these records. Time marker $=$ $10 \mathrm{~s}$. Bottom: diving bradycardia associated with forced submergence and release of bradycardia associated with voluntary return to air breathing. Time marker $=1 \mathrm{~s}$.
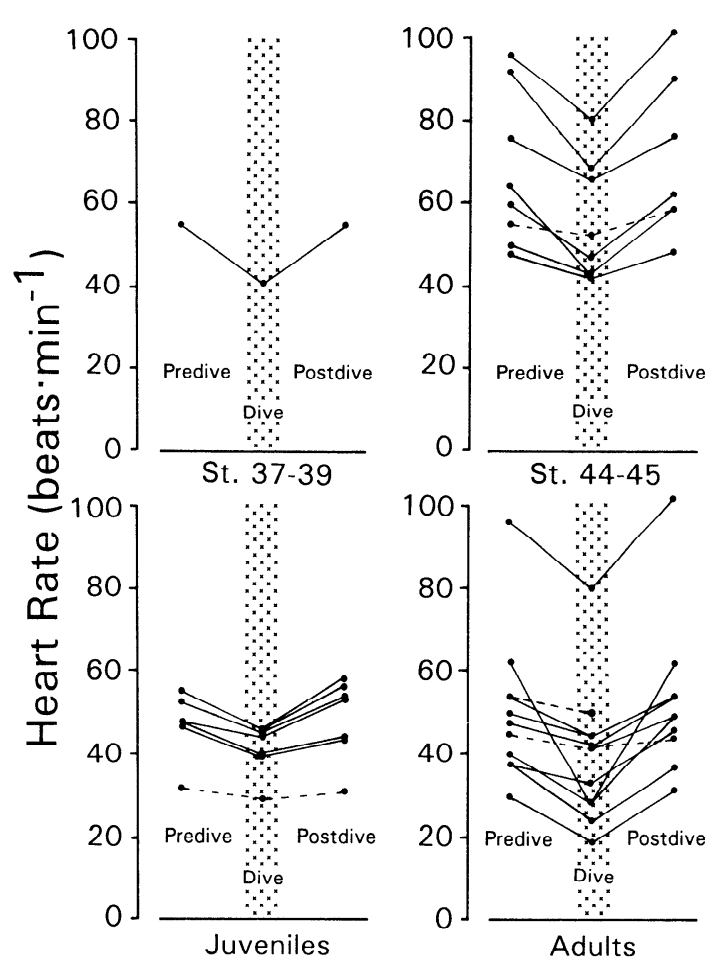

Fig. 3. Heart rate responses to diving in 4 developmental stages of larval $P$. paradoxsus. Dashed lines indicate animals in which forced diving caused $<10 \%$ reduction in heart rate, which was too small to qualify as diving bradycardia. See text for additional details.

seven showed a bradycardia within $20 \mathrm{~s}$ of the onset of diving. Mean values $( \pm S D)$ of $f_{H}$ before a forced dive, during the first $5 \mathrm{~min}$ of the dive, and after the dive in the eight stage 42-45 larvae examined were $68 \pm 19,55 \pm 15$, and $71 \pm 19$ beats/min, respectively.

No consistent changes in arterial blood pressure were evident during forced dives in these larvae.

Juveniles and adults. Juveniles $(<15 \mathrm{~g})$ and adults $(>23$ g) showed very similar respiratory behavior, usually floating at the water surface and continuously ventilating their lungs. When spontaneous voluntary dives occurred, bradycardia developed within 20-30 s and was usually more profound than in forced dives (compare $f_{H}$ during 


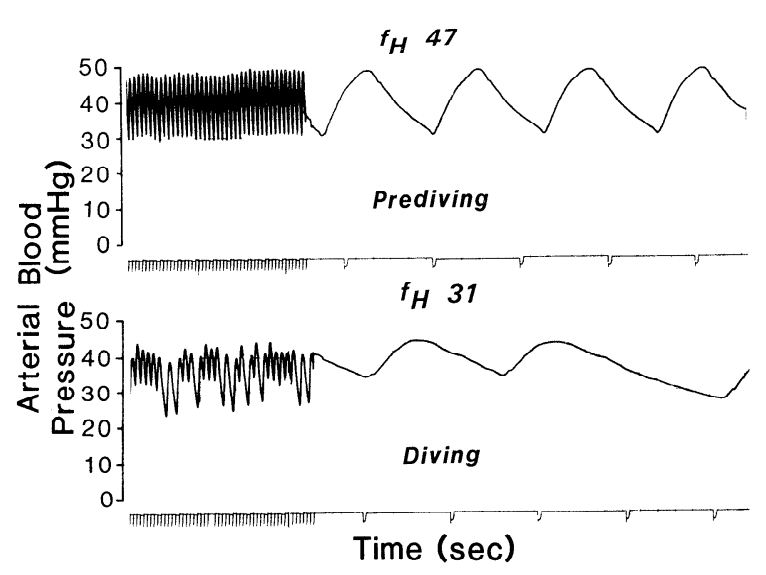

Fig. 4. Arterial blood pressure and heart rate in a stage $45(8.9-\mathrm{g})$ larval Pseudis before diving (top) and 5 min into a forced dive (bottom).

voluntary diving in Fig. 5 with data on forced diving in Fig. 3, bottom right).

Forced diving produced a bradycardia of variable magnitude in 6 of 7 juveniles and 8 of 10 adults tested (Fig. 3). As with stage 44-45 larvae, there was considerable variation in predive $f_{\mathrm{H}}$. Heart rate in most juveniles and adults tended to decrease progressively during the dive (Fig. 5). Extra-long diastolic intervals were common during both voluntary and forced diving in juveniles and adults (but see Fig. 5 for exception). No consistent pattern of change in arterial blood pressure accompanied diving in either juveniles or adults.

Mean values $( \pm S D)$ of $f_{H}$ before a forced dive, during the first $5 \mathrm{~min}$ of the dive, and after the dive in seven juvenile Pseudis were $48 \pm 8,41 \pm 6$, and $48 \pm 10$ beats/ min, respectively. The corresponding values in the 10 adults examined were $46 \pm 10,35 \pm 10$, and $48 \pm 9$ beats/min.

\section{DISCUSSION}

\section{Ontogenetic Changes in Arterial Blood Pressure}

The heart of all vertebrate embryos originates as a simple pulsatile tube that then undergoes a pattern of $\mathrm{S}$ folding to produce a heart of three or more chambers. The first anatomic rudiments of the heart do not carry out coordinated beating, and intuitively the pressure in the lumen of the early embryonic heart tube must be at or near $0 \mathrm{mmHg}$. Blood flow from the heart will begin to occur only when systolic pressure rises significantly above pressure in the peripheral arterial circulation. As cardiac

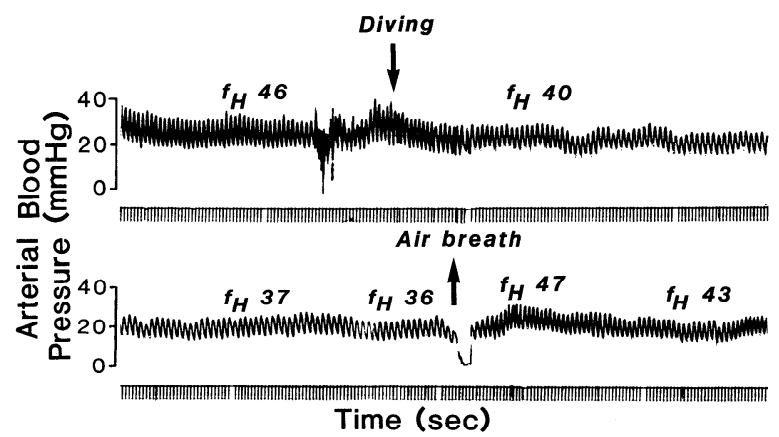

Fig. 5. Arterial blood pressure and heart rate measured before, during, and after a voluntary dive in a 14.5 -g juvenile Pseudis. development continues, ventricular pressures will rise, eventually reaching adult levels. Consequently, a rise in systemic blood pressure is inherent in the development of both vertebrate and invertebrate cardiovascular systems. Although measurements are few, an ontogenetic rise in systemic arterial blood pressure, verified by either intracardiac or central arterial pressure measurements, has been described in the skate Raja erinacea (21), the bullfrog (22), and chicken embryos (for reviews see Refs. 12, $16,27)$.

Given these data, a rise in blood pressure during development in P. paradoxsus is to be anticipated. Nonetheless, several aspects of the blood pressure measurements of the present study deserve emphasis. First, the speed and magnitude of the blood pressure changes were dramatic. The developmental transition in Pseudis from stages $37-39$ to $42-45$ occurred in a matter of a few days, and, likewise, the transition from stage 42-45 larvae to juvenile took place within 1 or 2 wk. Within this short period, mean systemic arterial blood pressure in Pseudis increased by threefold, from 10 to $30 \mathrm{mmHg}$. The underlying mechanism is unknown but could involve several factors. For example, a rise in peripheral resistance with maintained cardiac output would lead to an increased arterial blood pressure. Alternatively, if peripheral resistance stayed the same but an increased cardiac output was required, then by necessity an increased arterial blood pressure would result. Peripheral resistance of the chick embryo (widely assumed to be a model for vertebrate circulation in general) decreases during development (12), possibly because aortic diameter decreases and more resistance vessels are added, thus increasing the total cross-sectional area of the circulation. Pseudis, with its unorthodox decrease in body mass during much of its life cycle, may depart from the findings reported for chick embryos, but additional data on blood flow will be required to determine how peripheral resistance changes during development in Pseudis. Regardless of the reason for the rise in systemic arterial blood pressure recorded in Pseudis, it is likely (but as yet untested) that Pseudis exhibits an ontogenetic change in heart size, cardiac wall thickness, and other factors that will contribute to increased blood pressure generation. Metamorphosis from larva to adult in the bullfrog is correlated with a significant mass-specific rise in heart mass (8) concomitant with rising blood pressure. A morphometric analysis of the circulation of Pseudis would be particularly interesting given the decline in body size but a possible rise in heart mass (attendant with higher pressures).

The developmental changes in systemic arterial blood pressure in Pseudis are set against a backdrop of large body mass changes. Change in body mass per se can produce large changes in many physiological functions (see Refs. 23, 24). Interspecific comparisons in adult mammals indicate that systemic arterial blood pressure is essentially independent of body mass (18). In an intraspecific study including both bullfrog larvae and adults, systolic blood pressure increased with body mass, scaling to body mass with the exponent 0.61 (22). The situation appears more complex in Pseudis, since blood pressure increases even as body mass decreases sharply during 
larval development from stages 37-39 to 44-45 (Fig. 1). On the other hand, blood pressure remains the same during the increase in body mass from juvenile to adult stage. Although body mass will certainly alter some cardiovascular variables due to its ultimate effect on cumulative blood vessel length and thus on peripheral resistance, in Pseudis there are clearly cardiovascular factors much more dominant than body mass that determine mean arterial blood pressure.

\section{Ontogeny of Diving Bradycardia}

Changes in heart rate associated with intermittent air breathing is a basic cardiac response in virtually all classes of vertebrates as adults (for recent reviews see Refs. $4,10,26)$. By contrast, the ontogeny of this response is very poorly documented for any vertebrate. In amphibians, an increase in heart rate during air breathing has been reported for the larvae of the tiger salamander $\mathrm{Am}$ bystoma tigrinum (15). Larvae of the bullfrog have mechanisms in place for regulation of heart rate [e.g., vagal innervation of the heart exists by midlarval development (5)], but "ventilation tachycardia" or "diving bradycardia" has not been recorded for this species $(5,28)$. $P$. paradoxsus showed a diving bradycardia response as early as the predominantly water-breathing larval stage 37 (Fig. 3). As evident in Fig. 3, late larval, juvenile, and adult stages all exhibit a similar pattern and magnitude of diving bradycardia as well as postdive tachycardia. Moreover, the onset of diving bradycardia occurs within $20 \mathrm{~s}$ of diving in all developmental stages examined. The occurrence of bradycardia during voluntary dives as well as a tachycardia during bouts of voluntary air breathing in animals floating at the surface suggests that heart rate changes are a part of the normal cardiorespiratory interactions in Pseudis in both late-stage larvae and adults. Because only one stage 37-39 larvae showed intermittent lung ventilation (and thus had a "diving" vs. "nondiving" state), a quantitative assessment of diving bradycardia in these earlier larval stages could not be made. However, the clear presence of both a diving bradycardia and a startle reflex in at least that individual indicates that the cardiovascular system of Pseudis can respond reflexly to complex stimuli as early as stage 37 .

How these cardiac reflexes are mediated is not known. The startle reflex upon body contact could involve the lateral line system generally found in anuran larvae (7). The diving bradycardia and other frequency modulations may reflect the presence of pulmonary mechanoreceptors and chemoreceptors [observed in mid to late larval stages of the bullfrog (28)]. Circulating catecholamines are unlikely to be involved in the cardiac response to diving, since the initiation of bradycardia and the return to predive $f_{H}$ usually occur within a few beats of submergence, too fast for catecholamines to clear from plasma or be added to plasma, respectively. However, variation in circulating catecholamine levels (or large variations in vagal and sympathetic "tone" to the heart) could explain the almost twofold variation in "resting" $f_{H}$ before diving in stage 44-45 larvae (Fig. 3). That such variation in $\mathrm{f}_{\mathrm{H}}$ does exist (regardless of the particular neural or hormonal mechanism that causes it) is noteworthy, for it does in- dicate the presence of cardiac modulating mechanisms by stages $44-45$.

Diving bradycardia in adult bullfrogs has been described in many studies (see Refs. 5, 20, 25). The present study documents this phenomenon in adult Pseudis (not unexpectedly), and the general pattern of heart rate change during diving is essentially the same as in other anurans. From a physiological perspective, the major paradox involving this species is that the small size of the adult may limit future physiological studies of the terminal developmental stage, a situation generally opposite to that in studies of other anurans, where the adults are the most intensively studied. However, the unusually large size of the larva of Pseudis offers many opportunities for developmental biologists, who up to this time have had to eschew in vivo measurements in premetamorphic developmental stages of aquatic anuran larvae.

The research supported in this study was supported by a travel grant to W. W. Burggren and an equipment grant (89/2857-5) to M. L. Glass provided by FAPESP (Brazil).

Address for reprint requests: W. W. Burggren, Dept. of Biological Sciences, University of Nevada, Las Vegas, 4505 Maryland Parkway, Las Vegas, NV 89154-4004.

Received 1 April 1991; accepted in final form 3 March 1992.

\section{REFERENCES}

1. Burggren, W. W. "Air gulping" improves blood oxygen transport during aquatic hypoxia in the goldfish, Carassius auratus. Physiol. Zool. 55: 327-334, 1982.

2. Burggren, W. W. Pulmonary plasma filtration in the turtle: a wet vertebrate lung? Science Wash. DC 215: 77-78, 1982.

3. Burggren, W. W. Transition of respiratory processes during amphibian metamorphosis: from egg to adult. In: Respiration and Metabolism of Embryonic Vertebrates, edited by R. S. Seymour. Dordrecht, Netherlands: Junk, 1984, p. 31-54.

4. Burggren, W. W. Cardiovascular responses to diving and their relation to lung and blood oxygen stores in vertebrates. Can. J. Zool. 66: 20-28, 1988.

5. Burggren, W. W., and M. Doyle. Ontogeny of heart rate regulation in the bullfrog, Rana catesbeiana. Am. J. Physiol. 251 (Regulatory Integrative Comp. Physiol. 20): R231-R239, 1986.

6. Burggren, W. W., and M. Doyle. The action of acetylcholine upon heart rate changes markedly with development in the bullfrog. J. Exp. Zool. 240: 137-140, 1986.

7. Burggren, W. W., and J. J. Just. Developmental changes in amphibian physiological systems. In: Environmental Physiology of Amphibians, edited by M. E. Feder and W. W. Burggren. Chicago, IL: Univ. of Chicago Press. In press.

8. Burggren, W. W., and A. W. Pinder. Ontogeny of cardiovascular and respiratory physiology in lower vertebrates. Annu. Rev. Physiol. 53: 107-135, 1991.

9. Burggren, W. W., A. W. Smits , and B. E. Evans. Arterial oxygen homeostasis during diving in the turtle Chelodina longicollis. Physiol. Zool. 62: 668-686, 1989.

10. Butler, P. J. The exercise response and the "classical" diving response during natural submersion in birds and mammals. Can. J. Zool. 66: 29-39, 1988.

11. Cais, A. Aspectos da Biologica e Ontogẽnese de Pseudis paradoxus (Linné, 1758)(Amphibia-Pseudidae) ( $\mathrm{PhD}$ dissertation). Rio Claro, Brazil: Universidade Estadual Paulista "Julio de Mesquita Filho," 1982.

12. Clark, E. B. Functional aspects of cardiac development. In: Growth of the Heart in Health and Disease, edited by R. Zak. New York: Raven, 1984, p. 377-386.

13. Feder, M. E., and W. W. Burggren. Cutaneous gas exchange in vertebrates: design, patterns, control and implications. Biol. Rev. 60: 1-45, 1985.

14. Feder, M. E., and A. W. Pinder. Ventilation and its effect on "infinite pool" exchangers. Am. Zool. 28: 973-984, 1988. 
15. Heath, A. G. Cardiac responses of larval and adult tiger salamanders to submergence and emergence. Comp. Biochem. Physiol. A. Comp. Physiol. 65: 439-444, 1980.

16. Hu, N., and E. B. Clark. Hemodynamics of the stage 12 to stage 29 chick embryo. Circ. Res. 65: 1665-1670, 1985.

17. Gosner, K. L. A simplified table for staging anuran embryos and larvae with notes on identification. Herpetologica 16: 183-190, 1960.

18. Gunther, B., and B. Leon De La Barra. Physiometry of the mammalian circulatory system. Acta Physiol. Lat. Am. 5: 169-699, 1966.

19. Kimmel, P. B. Ontogeny of Cardiovascular Control Mechanisms in the Bullfrog, Rana catesbeiana (PhD dissertation). Amherst: University of Massachusetts, 1990.

20. Lillo, R. W. Heart rate and blood pressure in bullfrogs during prolonged maintenance in water at low temperature. Comp. Biochem. Physiol. 65: 251-253, 1980.

21. Pelster, B., and W. E. Bemis. Ontogeny of heart function in the little skate, Raja erinacea. J. Exp. Biol. 156: 387-398, 1991.
22. Pelster, B., and W. W. Burggren. Central arterial hemodynamics in larval bullfrogs (Rana catesbeiana): developmental and seasonal effects. Am. J. Physiol. 260 (Regulalory Integrative Comp. Physiol. 29): R240-R246, 1991.

23. Peters, R. H. The Ecological Implication Of Body Size. New York: Cambridge Univ. Press, 1983.

24. Schmidt-Nielsen, K. Scaling: Why Is Animal Size So Important. New York: Cambridge Univ. Press, 1984.

25. Shelton, G., and R. G. Boutilier. Apnoea in amphibians and reptiles. J. Exp. Biol. 100: 245-274, 1982.

26. Smatresk, N. J. Control of the respiratory mode in air-breathing fishes. Can. J. Zool. 66: 144-151, 1988.

27. Tazawa, H. Measurement of blood pressure of chick embryo with an implanted needle catheter. J. Appl. Physiol. 51: 1023-1026, 1981.

28. West, N. H., and W. W. Burggren. Reflex interactions between aerial and aquatic gas exchange organs in the larval bullfrog. Am. J. Physiol. 244 (Regulatory Integrative Comp. Physiol. 13): R770-R777, 1983.

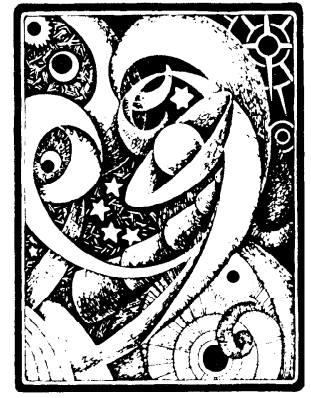

